\title{
Frailty status, acute coronary syndrome and all-cause mortality in the elderly
}

\author{
Shaomin $\mathrm{Zhang}^{1} \cdot$ Jinhui $\mathrm{Wu}^{1}$ (D) \\ Received: 9 April 2020 / Accepted: 11 May 2020 / Published online: 24 May 2020 \\ (c) Springer Nature Switzerland AG 2020
}

Keywords Frailty $\cdot$ Acute coronary syndrome $\cdot$ All-cause mortality $\cdot$ Elderly

\section{In reply}

Thanks for Dr. Kawada's concern [1]. Dr. Kawada raise two important issues regarding our review [2] the role of prefrailty and gender in the effect of frailty on all-cause mortality in patients with acute coronary syndromes (ACS).

Little attention has been paid to the role of prefrailty on risk assessment in older patients with ACS. It is important to note that the prevalence of comorbidities, the risk conditions, and mortality progressively increased along with the degree of frailty in patients from this series [3]. Therefore, prefrailty should be considered as an intermediate status between robust and frail patients. The earlier stage of frailty is reversible and could be remedied. Nutritional supplement with $25-30 \mathrm{~g}$ of high-quality protein per meal have slowed or prevented sarcopenia, a manifestation of prefrailty [4]. Meanwhile, physical activity interventions might play a pivotal role in the prevention of both CVD and frailty. More studies are required to confirm its function and establish standard exercise prescriptions. The frailty as a therapeutic goal intervened by nonpharmacological means is the future hotspot of research.

The prevalence of frailty in older patients is about twice in women than in men. Female sex is an independent predictor of frailty in elderly patients with ACS, and it is also associated with higher mortality [5]. Several differences could explain this sex-related difference. The association of female sex with more atypical symptoms. Older women without a typical chest pain are commonly underdiagnosed and mistreated. A study showed that women have lower revascularization rates than men [6], and these patients who do not undergo coronary angiography and revascularization seem

Jinhui Wu

wujinhui@scu.edu.cn

1 The Center of Gerontology and Geriatrics, West China Hospital, Sichuan University, Chengdu 610041, China to have worse prognosis. Further studies are needed to elucidate the best management of frail older women with ACS.

Funding None.

\section{Compliance with ethical standards}

Conflict of interest No conflict of interest exists in the submission of this manuscript, and the manuscript is approved by all authors for publication.

Statement of human and animal rights Not applicable.

\section{References}

1. Kawada T (2020) Frailty status, acute coronary syndrome and all-cause mortality in the elderly. Aging Clin Exp Res. https://doi. org/10.1007/s40520-020-01566-4

2. Zhang S, Meng H, Chen Q et al (2020) Is frailty a prognostic factor for adverse outcomes in older patients with acute coronary syndrome? Aging Clin Exp Res. https://doi.org/10.1007/s4052 0-019-01311-6

3. Alegre O, Formiga F, Lopez-Palop R et al (2018) An easy assessment of frailty at baseline independently predicts prognosis in very elderly patients with acute coronary syndromes. J Am Med Dir Assoc 19:296-303

4. Paddon-Jones D, Rasmussen BB (2009) Dietary protein recommendations and the prevention of sarcopenia. Curr Opin Clin Nutr Metab Care 12:86-90

5. Vicent L, Ariza-Solé A, Alegre O et al (2018) Octogenarian women with acute coronary syndrome present frailty and readmissions more frequently than men. Eur Heart J Acute Cardiovasc Care. https://doi.org/10.1177/2048872618798226

6. De Carlo M, Morici N, Savonitto S et al (2015) Sex-related outcomes in elderly patients presenting with non-ST-segment elevation acute coronary syndrome: insights from the Italian elderly ACS study. JACC Cardiovasc Interv 8:791-796

Publisher's Note Springer Nature remains neutral with regard to jurisdictional claims in published maps and institutional affiliations. 